Available online at GSC Online Press Directory

GSC Biological and Pharmaceutical Sciences

e-ISSN: 2581-3250, CODEN (USA): GBPSC2

Journal homepage: https://www.gsconlinepress.com/journals/gscbps

(RESEARCH ARTICLE)

\title{
Toxicity of two groups of pesticides against the mosquito Aedes aegypti
}

\author{
Mohammed Rashed Al Zahrani 1, *, Fatehia Nasser Gharsan 2, Khalid Mohammed Al-Ghamdi ${ }^{1}$, Jazem \\ Abdullah Mahyoub ${ }^{1}$ and Tariq Saeed Alghamdi ${ }^{2}$
}

1 Biology Department, Faculty of Sciences, King Abdulaziz University, Elehtefalat Street, Jeddah -80203-22230, Saudi
Arabia.

${ }^{2}$ Biology Department, Faculty of Sciences, Al-Baha University, King Saud Street, Al-Baha 22888/998, Saudi Arabia.

Publication history: Received on 06 October 2020; revised on 15 October 2020; accepted on 20 October 2020

Article DOI: https://doi.org/10.30574/gscbps.2020.13.1.0334

\begin{abstract}
The mosquito Aedes aegypti (Linnaeus) (Diptera: Culicidae) is a vector for several pathogens that affect human health worldwide. Therefore, mosquito control is the best approach to prevent disease outbreaks. In this milieu, it is preferable to evaluate the effectiveness of chemical pesticides at regular intervals to identify the most effective ones and use them during the outbreaks of diseases and spread of pests. Here, we aimed to study the toxicity of six pesticides, which are classified under two groups, namely pyrethroids and organophosphates, against $A$. aegypti mosquitoes to improve disease control in Saudi Arabia. Hortak was the most effective in larval mosquito control (LC50 = 0.0031 ppm), followed by Aquapal Super $20 \mathrm{EW}(\mathrm{LC} 50=0.0389 \mathrm{ppm})$, whereas Solfac was the least effective (LC50 = 0.1119 ppm). In addition, the sensitivity of the tested larvae to Safrotin and Keen 600 EC was 8.1 and 58.9 times higher than that to Resfin-5, which was the least effective, respectively. Hortak and Safrotin exhibited the highest toxicity against the larvae of $A$. aegypti. Our findings confirm that the tested pesticides can be used in mosquito-control programs during epidemic outbreaks and emergency.
\end{abstract}

Keywords: Bioassay; Larva; LC50; Organophosphate; Pyrethroid.

\section{Introduction}

Mosquitoes are distributed worldwide and inhabit diverse environmental conditions [1]. They are an annoyance to human beings owing to their painful bites [2]. Moreover, mosquitoes transmit several pathogens. Aedes aegypti (Linnaeus) (Diptera: Culicidae) mosquitoes can grow indoors on small quantities of clean or polluted water and transmit several pathogens such as dengue, yellow fever, chikungunya, and Zika viruses, thus threatening human life [3, 4, 5] . In 2019, the World Health Organization (WHO) announced that approximately 50 million people a year develop dengue fever and 2.5 billion people live in endemic areas. In 2013, the infection rate increased to 390 million people [6]. It has been estimated that the number of people at risk of dengue fever is 3.9 million in 128 countries [7]. An estimated 500 000 people suffer from severe dengue fever each year, and approximately $2.5 \%$ of them die of it [8]. Furthermore, there are expectations of increase in the number of people infected with mosquito-borne diseases, especially dengue fever, which is one of the most important viral diseases in several countries [9]. In the western and southern regions of Saudi Arabia, dengue has become endemic [10, 11, 12]. In 2011, there was a pandemic, with 4411 reported cases, of which eight died [13, 14]. In 2009, dengue fever was reported in other areas such as Medina, Asir, and Jazan 2013 [15]. During outbreaks, rapid intervention is needed to eliminate mosquitoes and reduce their spread. According to the WHO [16], mosquito control relies on reducing the population density of mosquitoes in the environment to the extent that they do not cause any health problems, as an unpleasant pest or a disease vector. Therefore, the WHO recommends that control

\footnotetext{
* Corresponding author Mohammed Rashid Al Zahrani

Biology Department, Faculty of Sciences, King Abdulaziz University, Elehtefalat Street, Jeddah 80203-22230, Saudi Arabia. 
programs should be continued, while further developing the traditional methods. Although many types of pesticides are available, which are still highly effective against mosquitoes, their continued use has led to the emergence of resistance in mosquitoes against some pesticides [17]. The problem of mosquito resistance to chemical pesticides is increasing worldwide [18, 19, 20, 21, 22]. Therefore, the effectiveness of pesticides used in the control programs should be evaluated on a regular basis to ensure that appropriate decisions are made when urgent interventions are needed [23], especially, considering the limited studies on pesticides used in mosquito control programs in the western and southern regions of Saudi Arabia. Biological assessment of several pesticides against mosquito species has been conducted [24, 25, 26, 27]. In Colombian-Caribbean Region, Maestre-Serrano et al. [28] determined the susceptibility and resistance of A. aegypti mosquitoes to numerous organophosphorus pesticides, pyrethroids, and DDT.

In the present study, we aimed to assess the effectiveness of two groups of pesticides, namely pyrethroids and organophosphates, in order to identify the most efficient ones for effective use under emergency situations. The toxicity of three pyrethroid insecticides, namely, Aquapal Super 20EW, Solfac EC 050, and Hortak 50 EC, and organophosphate pesticides, namely, Safrotin, Keen 600 EC, and Resfin, against A. aegypti larvae was measured after 24 h of pesticide treatment. The insecticidal effect of these pesticides on the larvae of $A$. aegypti mosquitoes was evaluated by calculating the lethal concentration of 50\% and 90\% (LC50 and LC90, respectively).

\section{Material and methods}

\subsection{Specimen collection}

A strain of A. aegypti was collected from Taif Governorate (western region of Saudi Arabia). A plastic dipper equipped with aluminum arm (160 cm length) was used to collect samples from water in mosquito-positive sites such as watersheds of swamps and valleys. The larvae were placed in 300-mL plastic jars, and then transferred to the laboratory at $27 \pm 1{ }^{\circ} \mathrm{C}$ and $70 \% \pm 5 \%$ relative humidity, with $14: 10 \mathrm{~h}$ (L:D) photoperiod.

\subsection{Larvae rearing}

The larvae were reared in glass trays $(20 \mathrm{~cm} \mathrm{~L} \times 30 \mathrm{~cm} \mathrm{~W} \times 6 \mathrm{~cm} \mathrm{D})$ filled with water and fed dried bread powder, instant yeast, and dried milk in the ratio of $1: 1$. The newly formed pupae were removed from the trays to a plastic cup containing water and placed into screened cages $(30 \mathrm{~cm} \times 30 \mathrm{~cm} \times 30 \mathrm{~cm})$, where the adult emerged later. The adults were fed animal blood (pigeon) for $2 \mathrm{~h}$ a day for three days. The following generations were also reared to obtain abundant larvae for experimental purpose [29].

\subsection{Material used and tested insecticides}

The sensitivity of A. aegypti larvae against conventional pesticides was evaluated to determine the effectiveness of the pesticides by calculating the percentage of mortality.

Conventional pesticides tested against $A$. aegypti. The pyrethroids and organophosphates presented in Table 1 were used against $A$. aegypti larvae.

The standard stock solution of the selected pesticides was prepared by adding $0.1 \mathrm{~mL}$ of pesticide into $100 \mathrm{~mL}$ of distilled water in a standard flask $(100 \mathrm{~mL})$

\subsection{Bioassay}

The larval sensitivity test, following the WHO standard method [30], with pyrethroids and organophosphates, was carried out by taking into account the LC50 and LC90 for the treated larvae. Probability regression lines were drawn for the tested insecticides and statistical parameters were also calculated using the method of [31]. A series of standard solutions was prepared at different concentrations selected according to the method used by the WHO (Table 1). 
Table 1 Conventional pesticides tested against $A$. aegypti larvae.

\begin{tabular}{|c|c|c|c|c|}
\hline & Pesticide & Active ingredient & Chemical structure & Group \\
\hline 1 & Solfac EC 50 & Cyfluthrin 50\% & & Pyrethroid \\
\hline 2 & Hortak EC 50 & $\begin{array}{l}\text { Cypermethrin } \\
10 \% \mathrm{EC}+\text { Tetramethrinl1.5\%)( }\end{array}$ & & Pyrethroid \\
\hline 3 & $\begin{array}{l}\text { Aquapal Super } \\
20 \mathrm{EW}\end{array}$ & Deltamethrin 2\% & & Pyrethroid \\
\hline 4 & Safrotin $20 \mathrm{MC}$ & Propetamphos $20 \%$ & & Organophosphate \\
\hline 5 & Keen 600 EC & Diazinon $60 \%$ & & Organophosphate \\
\hline 6 & Resfin & Chlorpyrifos methyl 30\% & & Organophosphate \\
\hline & & & & \\
\hline
\end{tabular}

The experiments were conducted using white plastic plates $(11 \mathrm{~cm}$ diameter, $4 \mathrm{~cm}$ depth, $250 \mathrm{~mL}$ volume) filled with $100 \mathrm{~mL}$ of water for each pesticide. There were five replicates per concentration. Twenty larvae (at the end of the third and beginning of the fourth instar stages) were placed in each dish. In addition to the treated samples, five control replicates were used; the larvae in the control plates were provided food during the test. After $24 \mathrm{~h}$ of treatments, the dead larvae, which did not move when touched by an autopsy needle in the siphon or neck area, were counted. The moribund larvae were also counted, which could not rise to the surface of the water or sink into the water when the water was shaken.

Abbott's equation [32] was used to adjust the death rate in case of death of more than $5 \%$ and less than $20 \%$ of the control larvae. LdP-Line software (Ehab Bakr) was used to draw toxicity lines and to infer other statistical parameters such as LC50, IC90, and Slop value, and $\chi 2$ data were obtained according to the method of [33].

\section{Results}

\subsection{Pyrethroid insecticides}

The results presented in Table 2 and Figure 1 show a direct correlation between increasing concentrations of pesticides and percentage of larval death. However, Solfac EC 50 was found to be the least effective pesticide against $A$. aegypti mosquito. The effective concentrations of pesticides ranged from 0.05 to $0.5 \mathrm{ppm}$ and larval mortality ranged from $21.429 \%$ to $89.796 \%$, respectively. On the contrary, the toxicity lines in the graphs of the three tested pesticides and their statistical constants (see Tables 2 and 3) showed a difference between the concentrations required to kill $50 \%$ and 
$90 \%$ of the treated larvae (LC50 and LC90). For Hortak, the LC50 was 0.0031 ppm (95\% confidence interval 0.00270.0036), whereas the LC90 was $0.0139 \mathrm{ppm}$ (95\% CI 0.0111-0.019). With respect to Solfac, higher concentrations were required to kill $50 \%$ of the larvae ( $\mathrm{LC} 50=0.1119$ and $95 \% \mathrm{CI}=0.0958-0.1289$ ), and the lethal concentration, that is, LC90, was 0.04943 ppm (95\% CI 0.3908-0.6814).

The resistance ratio (RR) and toxicity line values showed that the activity of Hortak was 12.6 and 36.1 times higher than that of Aquapal Super and Solfac, respectively. The values of Hortak, Aquapal Super, and Solfac were 7.4072, 1.0415, and 2.1924, which were less than the $\chi 2$ value (7.8) at a significance level of 0.05 and degree of freedom (n) of 3 (Table 2 and Figure 1).

Table 2 Sensitivity of the fourth instar larvae of $A$. aegypti after exposure to different concentrations of the pyrethroid pesticides for $24 \mathrm{~h}$.

\begin{tabular}{|c|c|c|c|c|c|c|}
\hline & \multicolumn{2}{|l|}{ Hortak } & \multicolumn{2}{|c|}{ Aquapal Super $20 \mathrm{EW}$} & \multicolumn{2}{|l|}{ Solfac } \\
\hline & $\begin{array}{l}\text { Concentration } \\
(\mathrm{ppm})\end{array}$ & Mortality \% & $\begin{array}{l}\text { Concentration } \\
\text { (ppm) }\end{array}$ & Mortality \% & $\begin{array}{l}\text { Concentration } \\
(\mathrm{ppm})\end{array}$ & Mortality \% \\
\hline & 0.001 & 16 & 0.02 & 15.306 & 0.05 & 21.429 \\
\hline & 0.003 & 32 & 0.03 & 31.633 & 0.08 & 39.796 \\
\hline & 0.005 & 62 & 0.05 & 63.265 & 0.15 & 65.306 \\
\hline & 0.008 & 76 & 0.06 & 77.551 & 0.3 & 77.551 \\
\hline & 0.01 & 90 & 0.08 & 89.796 & 0.5 & 89.796 \\
\hline Control & \multicolumn{2}{|l|}{3} & \multicolumn{2}{|l|}{3} & \multicolumn{2}{|l|}{3} \\
\hline $\begin{array}{l}\mathrm{LC}_{50} \\
\text { (L. limit- U. } \\
\text { limit) }\end{array}$ & \multicolumn{2}{|l|}{$\begin{array}{l}0.0031 \\
0.0027-0.0036\end{array}$} & \multicolumn{2}{|l|}{$\begin{array}{l}0.0389 \\
0.0359-0.0419\end{array}$} & \multicolumn{2}{|l|}{$\begin{array}{l}0.1119 \\
0.0958-0.1289\end{array}$} \\
\hline $\begin{array}{l}\mathrm{LC}_{90} \\
\text { (L. limit- U. } \\
\text { limit) }\end{array}$ & \multicolumn{2}{|l|}{$\begin{array}{l}0.0139 \\
0.0111-0.019\end{array}$} & \multicolumn{2}{|l|}{$\begin{array}{l}0.0842 \\
0.0748-0.0983\end{array}$} & \multicolumn{2}{|l|}{$\begin{array}{l}0.4943 \\
0.3908-0.6814\end{array}$} \\
\hline Slope & \multicolumn{2}{|l|}{$1.9876 \pm 0.1856$} & \multicolumn{2}{|l|}{$3.818 \pm 0.3167$} & \multicolumn{2}{|l|}{$1.9866 \pm 0.1825$} \\
\hline Tabulated $\chi^{2}$ & \multicolumn{2}{|l|}{7.8} & \multicolumn{2}{|l|}{7.8} & \multicolumn{2}{|l|}{7.8} \\
\hline Calculated $\chi^{2}$ & \multicolumn{2}{|l|}{7.4072} & \multicolumn{2}{|l|}{1.0415} & \multicolumn{2}{|l|}{2.1924} \\
\hline
\end{tabular}

*The calculated $\chi 2$ value was less than the tabular value for significant difference and homogeneous strain and the line is a good representative of the results.

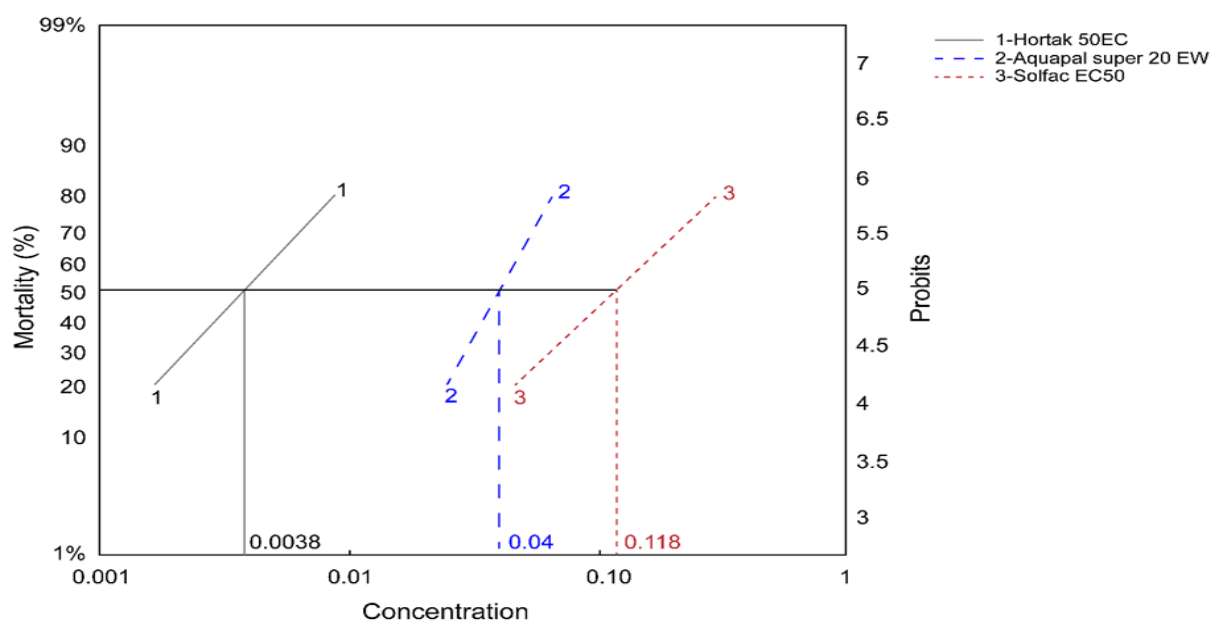

Figure 1 Toxicity line of pyrethroid insecticides against $A$. aegypti larvae after $24 \mathrm{~h}$ of treatment. 


\subsection{Organophosphate pesticides}

The results presented in Table 3 and Figure 2 show that the effective concentrations of Safrotin ranged from 0.01 to 0.2 ppm and the percentage of larval death at these concentrations ranged from $16 \%$ to $90 \%$, respectively, whereas the effective concentrations of Keen 600 EC ranged between 0.1 and $1 \mathrm{ppm}$ and the death percentage of the treated larvae was 13\%-94\%. For Resfin-5, the effective concentrations ranged between 0.5 and 15 ppm. The percentage of larval deaths corresponding to these concentrations ranged from $14 \%$ to $90 \%$.

Table 3 Sensitivity level of the fourth instar larvae of A. aegypti after exposure to different concentrations of organophosphate pesticides for $24 \mathrm{~h}$.

\begin{tabular}{|c|c|c|c|c|c|c|}
\hline & \multicolumn{2}{|l|}{ Safrotin } & \multicolumn{2}{|l|}{ keen $600 \mathrm{EC}$} & \multicolumn{2}{|l|}{ Resfin-5 } \\
\hline & $\begin{array}{l}\text { Concentration } \\
(\mathrm{ppm})\end{array}$ & $\begin{array}{l}\text { Mortality } \\
\%\end{array}$ & $\begin{array}{l}\text { Concentration } \\
(\mathrm{ppm})\end{array}$ & $\begin{array}{l}\text { Mortality } \\
\%\end{array}$ & $\begin{array}{l}\text { Concentration } \\
(\mathrm{ppm})\end{array}$ & $\begin{array}{l}\text { Mortality } \\
\%\end{array}$ \\
\hline & 0.01 & 16 & 0.1 & 13 & 0.5 & 14 \\
\hline & 0.03 & 32 & 0.3 & 35 & 1 & 33 \\
\hline & 0.06 & 62 & 0.6 & 68 & 5 & 68 \\
\hline & 0.09 & 76 & 0.9 & 81 & 10 & 78 \\
\hline & 0.2 & 90 & 1 & 94 & 15 & 90 \\
\hline Control & \multicolumn{2}{|l|}{3} & \multicolumn{2}{|l|}{0.0} & \multicolumn{2}{|l|}{3} \\
\hline $\begin{array}{l}\mathrm{LC}_{50} \\
\text { (L. limit- U. } \\
\text { limit) }\end{array}$ & \multicolumn{2}{|l|}{$\begin{array}{l}0.0444 \\
0.038-0.0514\end{array}$} & \multicolumn{2}{|l|}{$\begin{array}{l}0.3556 \\
0.214-0.5038\end{array}$} & \multicolumn{2}{|l|}{$\begin{array}{l}2.5899 \\
2.1148-3.1397\end{array}$} \\
\hline $\begin{array}{l}\mathrm{LC}_{90} \\
\text { (L. limit- U. } \\
\text { limit) }\end{array}$ & \multicolumn{2}{|l|}{$\begin{array}{l}0.2042 \\
0.1603-0.2817\end{array}$} & \multicolumn{2}{|l|}{$\begin{array}{l}1.199 \\
0.9474-2.7332\end{array}$} & \multicolumn{2}{|l|}{$\begin{array}{l}18.3821 \\
13.6955-26.8322\end{array}$} \\
\hline Slope & \multicolumn{2}{|l|}{$1.9329 \pm 0.1646$} & \multicolumn{2}{|l|}{$2.4282 \pm 0.1979$} & \multicolumn{2}{|l|}{$1.5058 \pm 0.1176$} \\
\hline Tabulated $\chi^{2}$ & \multicolumn{2}{|l|}{7.8} & \multicolumn{2}{|l|}{7.8} & \multicolumn{2}{|l|}{7.8} \\
\hline Calculated $\chi^{2}$ & \multicolumn{2}{|l|}{3.5614} & \multicolumn{2}{|l|}{10.5029} & \multicolumn{2}{|l|}{2.9717} \\
\hline
\end{tabular}

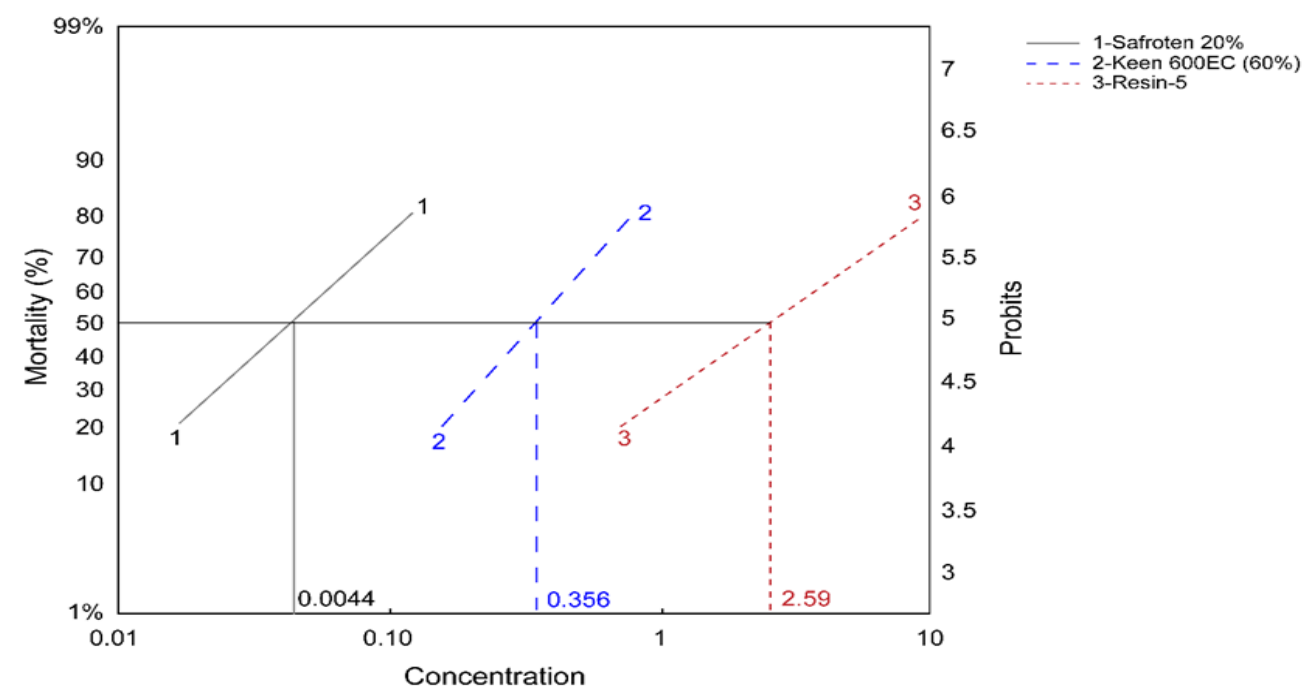

Figure 2 Toxicity line of organophosphate insecticides used against $A$. aegypti larvae after $24 \mathrm{~h}$ of treatment. 
There was a difference in the LC50 and LC90 when used against A. aegypti larvae. The LC50 of Safrotin was 0.0444 (95\% CI 0.038-0.0514) and LC90 was 0.2042 ppm (95\% CI 0.1603-0.2817). The LC50 of Keen 600 EC was 0.3556 ppm (95\% CI $0.214-0.05038)$, whereas the LC90 was 1.199 ppm (95\% CI $0.9474-2.7332$ ). The LC50 of Resfin-5 was 2.5899 (95\% CI 2.1148-3.1397) and LC90 was 18.3821 ppm (95\% CI 13.6955-26.8322).

In general, the results showed that the sensitivity of the tested larvae against Safrotin and Keen 600 EC was 8.1 and 58.9 times higher than that against Resfin-5, which was the least effective, respectively. This was confirmed by the tendency of toxicity line in the $y$-axis; the closer the toxicity line to the $y$-axis, the more effective the pesticide and more sensitive the larvae, and vice versa. The $\chi 2$ value of Safrotin (3.5614) was lower than that of the tabular value (7.8); the $\chi 2$ value of Keen 600EC and Resfin-5 was 10.5029 and 2.9717, which indicate homogeneity among the tested compounds.

\section{Discussion}

In the present study, the toxicity of organophosphorus (Safrotin, Keen 600 EC, and Resfin) and pyrethroid pesticides (Hortak, Aquapal Super, and Solfac) was evaluated and the exterminating effect of these pesticides on the fourth instar larvae of $A$. aegypti mosquito after $24 \mathrm{~h}$ was determined using the LC50 and LC90 values. The results of the present study showed that the response of the fourth instar larvae of $A$. aegypti against the tested pesticides depends on the type of pesticide used, action mechanism, and effective concentrations. This was confirmed by the differences in the percentage of larval mortality, which increased steadily with increasing concentration. The results of this study are consistent with those of previous studies and bioassay experiments against different species of mosquitoes. [25, 26, 27] have reported differences in the mortality of the fourth instar larvae according to the concentration and duration of exposure to pesticides. In the present study, Hortak EC50 was found to be more effective and more toxic than other pesticides, and its effective concentration range was $0.001-0.01 \mathrm{ppm}$, and the associated mortality rate was $90 \%$. For Aquapal Super (20 EW), the effective concentration range was $0.02-0.08 \mathrm{ppm}$ and the larval death rate was $15.306 \%-$ 89.796\%. Consistent with our findings, Al-Ghamdi et al. [34] and Al-Ghamdi and Mahyoub [17] confirmed the efficacy of pyrethroids against $A$. aegypti mosquitoes. Pyrethroids act as modifiers of the sodium channel and as toxins on the axons by blocking the sodium channels in both peripheral nervous systems and CNS, which results in frequent neurological flows causing paralysis and death of insects [35]. On the contrary, the results showed differences in the effect of organophosphorus pesticides on mosquito larvae. Safrotin was the most effective, followed by Keen 600 EC, whereas Resfin-5 was the least effective on the fourth instar larvae of mosquitoes. The results are consistent with those of Mahyoub et al. [36], who evaluated the effectiveness of a group of pesticides against Culex mosquito. Organophosphate pesticides bind to the cholinesterase and prevent it from binding to acetylcholine, causing its accumulation. It interferes with neuromuscular contact causing rapid tremors in the voluntary muscles, paralysis, and death due to failure of breathing [35].

\section{Conclusion}

The results of present study showed variation in mosquito response to different pesticides. Identification of the most effective pesticides is useful for reducing the problems associated with mosquito resistance to frequently used pesticides, especially during the spread of diseases. Our findings can be combined with those of other studies to create a database of pesticides that can be used in control programs.

\section{Compliance with ethical standards}

\section{Acknowledgments}

We are thankful to the team of the Research Unit of Dengue Fever and Vector Control, at King Abdulaziz University, for their support and providing facilities to complete this research.

\section{Disclosure of conflict of interest}

There is no conflict of interest.

\section{References}

[1] Reinhold JM, Lazzari CR, Lahondère C. Effects of the environmental temperature on Aedes aegypti Aedes albopictus Mosquitoes: A review. Insects. 2018; 9: 158. 
[2] Gharsan FN. A review of the bioactivity of plant products against Aedes aegypti (Diptera: Culicidae). Journal of Entomological Science. Jul 2019; 54(3): 256-74.

[3] Githeko AK, Lindsay SW, Confalonieri UE, Patz JA. Climate change and vector-borne diseases: a regional analysis. Bull World Health Organ. 2000; 78: 1136-1147.

[4] Hennessey M, Fischer M, Staples JE. Zika virus spreads to new areas-region of the Americas, May 2015-January 2016. Am J Transplant. 2016; 16: 1031-1034.

[5] Gregory CJ, Oduyebo T, Brault AC, Brooks JT, Chung KW, Hills S, Kuehnert MJ, Mead P, Meaney-Delman D, Rabe I, Staples E. Modes of transmission of Zika virus. The Journal of infectious diseases. 15 Dec 2017; 216(suppl_10): S875-83.

[6] Bhatt S, Gething PW, Brady OJ, Messina JP, Farlow AW, Moyes CL, Drake JM, Brownstein JS, Hoen AG, Sankoh O, Myers MF. The global distribution and burden of dengue. Nature. Apr 2013; 496(7446): 504-7.

[7] Brady OJ, Gething PW, Bhatt S, Messina JP, Brownstein JS, Hoen AG, Moyes CL, Farlow AW, Scott TW, Hay SI. Refining the global spatial limits of dengue virus transmission by evidence-based consensus. PLoS Negl Trop Dis. 7 Aug 2012; 6(8): e1760.

[8] World Health Organization. Dengue and severe dengue. [accessed December 19, 2019].

[9] Ashford DA, Savage HM, Hajjeh RA, McReady J, Bartholomew DM, Spiegel RA, Vorndam V, Clark GG, Gubler DG. Outbreak of dengue fever in Palau, Western Pacific, risk factor for injection. Am J Trop Med Hyg. 2003; 69: 135140 .

[10] Memish ZA, Albarrak A, Almazroa MA, Al-Omar I, Alhakeem R, Assiri A, Fagbo S, MacNeil A, Rollin PE, Abdullah N, Stephens G. Seroprevalence of Alkhurma and other hemorrhagic fever viruses, Saudi Arabia. Emerging infectious diseases. Dec 2011; 17(12): 2316.

[11] Khan NA, Azhar EI, El-Fiky S, Madani HH, Abuljadial MA, Ashshi AM, Turkistani AM, Hamouh EA. Clinical profile and outcome of hospitalized patients during first outbreak of dengue in Makkah, Saudi Arabia. Acta tropica. 1 Jan 2008; 105(1): 39-44.

[12] Alhaeli A, Bahkali S, Ali A, Househ MS, El-Metwally AA. The epidemiology of Dengue fever in Saudi Arabia: A systematic review. J Infect Public Health. 2016; 9: 117-124.

[13] Fakeeh M, Zaki AM. Virologic and serologic surveillance for dengue fever in Jeddah, Saudi Arabia, 1994-1999. Am J Trop Med Hyg. 2001; 65: 764-767.

[14] Aziz AT, Al-Shami SA, Mahyoub JA, Hatabbi M, Ahmad AH, Rawi CS. An update on the incidence of dengue gaining strength in Saudi Arabia and current control approaches for its vector mosquito. Parasit Vectors. 2014; 7: 258.

[15] Al-Azraqi TA, El Mekki AA, Mahfouz AA. Seroprevalence of dengue virus infection in Aseer and Jizan regions, Southwestern Saudi Arabia. Trans R Soc Trop Med Hyg. 2013; 107: 368-371.

[16] World Health Organization. Handbook for integrated vector management. ). Geneva, Switzerland: World Health Organization. 2012.

[17] Al-Ghamdi KM, Mahyoub JA. Seasonal abundance of Aedes aegypti (L.) in Jeddah Governorate with evaluating its susceptibility to some conventional and non-conventional insecticides. Met Env Arid Land Agri Sci. 2010; 21: 147-171.

[18] Katyal R, Tewari P, Rahman SJ, Pajni HR, Kumar K, Gill KS. Susceptibility status of immature and adult stages of Aedes aegypti against conventional insecticides in Delhi, India. Dengue Bull. 2001; 25: 84-87.

[19] Saleh MS, Kelada NL, El Meniawi FA, Zahran HM. Bacillus thuringiensis var. israelensis as sustained - release formulations against the mosquito Culex pipiens with special reference to the larvacidal effects of the bacterial agent in combination with three chemical insecticides. Alex J Agric Res. 2003; 48: 53-60.

[20] Nazny WA, Lee HL, Azhari AH. Adult and larval insecticide susceptibility status of Culex quinquefasciatus (Say) mosquitoes in Kuala Lumpur Malaysia. Trop Biomed. 2005; 22: 63-68.

[21] Tawatsin A, Thavara U, Bhakdeenuan P, Champoosn J. Field evaluation of Novaluron, A chitin synthesis inhibitor larvicide, against mosquito larvae in polluted water in urban areas of Bangkok, Thailand. Southeast Asian J Trop Med Public Health. 2007; 38: 434-438.

[22] Morales D, Ponce P, Cevallos V, Espinosa P, Vaca D, Quezada W. Resistance status of Aedes aegypti to deltamethrin, malathion, and temephos in Ecuador. J Am Mosq Control Assoc. 2019; 35: 113-122. 
[23] Panlawat A, Scott JE, Harrington LC. Insecticide susceptibility of Aedes aegypti and Aedes allopictus across Thailand. J Med Ent. 2005; 42: 821-825.

[24] Dia I, Diagne CT, Ba Y, Diallo D, Konate L, Diallo M. Insecticide susceptibility of Aedes aegypti populations from Senegal and Cape Verde Archipelago. Parasites \& vectors. 1 Dec 2912; 5(1): 238.

[25] Bandyopadhyay P, Sathe M, Tikar SN, Yadav R, Sharma P, Kumar A, Kaushik MP. Synthesis of some novel phosphorylated and thiophosphorylated benzimidazoles and benzothiazoles and their evaluation for larvicidal potential to Aedes albopictus and Culex quinquefasciatus. Bioorg Med Chem Lett. 2014; 24: 2934-2939.

[26] Aziz AT, Mahyoub JA, Rehman H, Saggu S, Murugan K, Panneerselvam C, Alrefaei MSS, Nicoletti M, Wei H, Canale A, Benelli G. Insecticide susceptibility in larval populations of the West Nile vector Culex pipiens L. (Diptera: Culicidae) in Saudi Arabia. Asian Pac J Trop Biomed. 2016; 6: 390-395.

[27] Alghamdi TS, Alghamdi KM, Mahyoub JA. Molting inhibitory and lethal effect of two juvenile hormone analogues on Culex pipiens L. J Entomol Zool Stud. 2017; 5: 217-220.

[28] Maestre-Serrano R, Gomez-Camargo D, Ponce-Garcia G, Flores AE. Susceptibility to insecticides and resistance mechanisms in Aedes aegypti from the Colombian Caribbean Region. Pestic Biochem Physiol. 2014; 116: 63-73.

[29] Imam H, Zarnigar GS, Seikh A. The basic rules and methods of mosquito rearing (Aedes aegypti). Trop Parasitol. 2014; 4: 53-55.

[30] World Health Organization. Instructions for determining the susceptibility or resistance of mosquito larvae to insecticides (No WHO/VBC. 81.807). Geneva, Switzerland: World Health Organization. 1981.

[31] Litchfield JJ, Wilcoxon F. A simplified method of evaluating dose-effect experiments. Journal of pharmacology and experimental therapeutics. 1 Jun 1949; 96(2): 99-113.

[32] Abbott WS. J Econ Entomol. A method of computing the effectiveness of an insecticide. 1925; 18: 265-7.

[33] Finney DJ. Probit analysis, Cambridge University Press. Cambridge, UK. 1971.

[34] Al-Ghamdi KMS, Al-Fifi ZI, Saleh MS, Al-Qhtani HA, Mahyoub JA. Insecticide susceptibility of Aedes aegypti the vector of dengue fever, in Jeddah governorate, Saudi Arabia. Biosci Biotech Res Asia. 2008; 5: 501-506.

[35] Ware GW. The pesticide book (5th ed.). Stamford: Thomson Corp. [32]. 2000.

[36] Mahyoub JA, Alsobhi AS, Al-Ghamdi K., Khatte NA, Al-Shami SA, Panneerselvam C, Murugan K, Nicoletti M, Canale A, Benelli G. Effectiveness of seven mosquito larvicides against the West Nile vector Culex pipiens (L.) in Saudi Arabia. Asian Pacific Journal of Tropical Disease. 2016; 6(5): 361-3. 